\title{
Searching for the Origins of Bere Barley: a Geometric Morphometric Approach to Cereal Landrace Recognition in Archaeology
}

\author{
M. Wallace ${ }^{1}$ (D) V V. Bonhomme ${ }^{2} \cdot$ J. Russell ${ }^{3} \cdot$ E. Stillman ${ }^{4} \cdot$ T. S. George ${ }^{3}$.

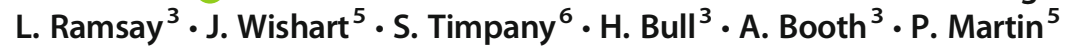

Published online: 16 November 2018

(C) The Author(s) 2018

\begin{abstract}
Bere is a landrace of barley, adapted to the marginal conditions of northern Scotland, especially those of the Northern and Western Isles. The history of bere on these islands is long and, in an era of diminishing landrace cultivation, bere now represents one of the oldest cereal landraces in Europe still grown commercially. The longevity of bere raises the possibility of using grain characteristics of present-day specimens to identify bere in the archaeological record. Geometric modern morphometric (GMM) analysis of grains from bere and other barley landraces is conducted to determine whether landraces can be differentiated on grain morphology. Results indicate that there are morphological differences between bere and other British and Scandinavian landraces, and between bere from Orkney and the Western Isles, both of which are apparent in genetic analysis. This finding paves the way for the identification of bere archaeologically, helping to establish its status as living heritage and securing its commercial future. More broadly, this work indicates the potential of grain GMM for the recognition of cereal landraces, permitting the ancestry and exchange of landraces to be traced in the archaeological record.
\end{abstract}

Keywords Barley · Cereals · Landraces · Archaeology · Archaeobotany · Agriculture · Genetics · Geometric morphometrics

\section{Introduction}

The spread of agriculture beyond the regions of cereal domestication in the Fertile Crescent of southwest Asia was a lengthy process crossing biogeographic boundaries. Following initial expansion through Anatolia and to Cyprus, domesticated crops reached southeast Europe c. 8500 yrs BP, and from there were dispersed along two main routes: a

Electronic supplementary material The online version of this article (https://doi.org/10.1007/s10816-0189402-2) contains supplementary material, which is available to authorized users.

M. Wallace

m.p.wallace@sheffield.ac.uk 
southern route along the Mediterranean, reaching the Iberian peninsula c. $7500 \mathrm{yrs} \mathrm{BP}$, and a northwards route passing through central Europe by c.7500 yrs BP and eventually reaching northern Scotland c.6000 yrs BP (Bocquet-Appel et al. 2009; Fort 2015). The continued viability of agriculture as it spread across Europe, especially along the latter northwards trajectory, required crops to adapt to environmental conditions starkly different to those under which they were first domesticated (Bogucki 2000; Bonsall et al. 2002; Halstead 1989). This is exemplified by adaptations in responsiveness to daylength with the northwards spread of agriculture (Jones et al. 2012) and observed adaptation to specific abiotic stresses (George et al. 2014; Schmidt et al. in prep.). Adaptation in crop species would have come about through periods of stable cultivation on the edges of new environments, leading to the emergence of new, locally adapted landraces.

Landraces are distinguished from modern varieties by their genetic diversity, long history of cultivation in specific regions and lack of formal breeding (Camacho Villa et al. 2006). Whilst modern plant breeding programmes have successfully produced high yielding varieties well-suited to intensive agriculture, this has been accompanied by a large decline in farmed landraces. Although landraces have previously been of importance to many local farming communities, they are 'invisible' to traditional archaeobotanical methods based on identification by eye (e.g. Pearsall 1989; Jacomet and Kreuz 1999). For example, most grains of domesticated barley preserved on archaeological sites are identified to the level of species (Hordeum vulgare L.). The presence of two-row (H. vulgare var. distichum) and six-row (H. vulgare var. hexasticum) forms can be inferred, at the assemblage level, by the ratio of straight (central) and twisted (lateral) grains, and naked forms (H. vulgare var. nudum) by the absence of hulls on grains, but further identification to the level of landrace is not attempted.

Information about ancient landraces can be inferred through ancient DNA (aDNA) analysis of preserved plant remains (Brown et al. 2015). Analysis of aDNA from barley grains has revealed new insights into the past use of the crop, including millennium-long landrace fidelity (Hagenblad et al. 2017) and the maintenance of local crop populations despite major human demographic change (Mascher et al. 2016; Palmer et al. 2009). These studies are restricted to grains preserved through desiccation, very rare in the archaeological record, or relatively recent deposits (up to c.3000 yrs. BP) of charred grain, owing to the poor preservation of DNA following charring (e.g. Bunning et al. 2012). As charring is the most common mode of archaeobotanical preservation, new approaches are required to broaden our knowledge of the role of landraces in ancient agriculture.

\section{Geometric Morphometrics as a New Approach to Landrace Recognition}

The recognition of landraces archaeologically requires the capture of information from preserved plant remains that is diagnostic between landraces. Subtle variations in grain shape, that cannot be quantified through identification-by-eye, may prove informative. Shape variation can be quantified using morphometrics, and in particular the analytically powerful field of geometric modern morphometrics (GMM). GMM gathers an array of highly versatile mathematical descriptors of shapes that turns homologous landmarks (two- or three-dimensionally arranged), outlines (open or closed) or surfaces into quantitative variables that can be analysed in multivariate statistical framework. GMM has additional merit for archaeological application in that it is non-destructive and low-cost. 
GMM is widely used, especially in the field of evolutionary biology (Cope et al. 2012; Mitteroecker and Gunz 2009; Adams et al. 2004; Zelditch et al. 2012), but also increasingly in archaeology, on both material culture (e.g. Lycett and von CramonTaubadel 2013) and biological remains (e.g. Perez et al. 2006; Ottoni et al. 2013). In archaeobotany, GMM has proven successful in identifying fruit crop varieties from the shape of pips of grapevine (Vitis vinifera L.) (Ucchesu et al. 2016; Pagnoux et al. 2015; Bouby et al. 2013; Terral et al. 2010; Orrù et al. 2013), and fruit stones of date palm (Phoenix dactylifera L.) (Terral et al. 2012), cherry (Prunus avium L.) (Burger et al. 2011) and olive (Olea europaea L.) (C. Newton et al. 2014; C. Newton et al. 2006; Terral et al. 2004). The identification of varieties for these taxa is not possible using traditional archaeobotanical techniques, and so variety recognition using GMM permits a re-evaluation of the economic and social role of these past crops (e.g. Pagnoux et al. 2015).

Large-seeded cereals were amongst the first domesticated crops, and were throughout much of prehistory the main calorie source, and continue to be of central importance in modern agricultural production. The use of GMM to investigate these important crops has been limited. Ros et al. (2014) demonstrated that GMM can be used to differentiate grains of two-row barley from those of six-row barley, across ten cultivars grown in the same conditions. Bonhomme et al. (2017) also demonstrated that the grains from three different samples can be differentiated for barley, as well as for einkorn (Triticum monococcum L.) and emmer (T. dicoccum Schübl.). Both of these studies considered the effects of charring on grain morphology, and show that the greatest effect of charring on grain is in terms of size, with grains typically shrinking by around 10\% (Charles et al. 2015). As size information can be discarded by the normalisation of outlines or landmarks in GMM, this aspect of charring is inconsequential. Charring also alters grain shape, however, resulting in rounder grains, but since the effect is consistent and predictable, it has been demonstrated to be of limited detriment to grain analysis. Ros et al. (2014) classified grains to their row type following linear discriminant analysis (LDA) and found that the leave-one-out (LOO) reclassification rate only reduced from 91 to $86 \%$ following charring at $250{ }^{\circ} \mathrm{C}$. In the Bonhomme et al. (2017) study, the more challenging reclassification to within-species samples was reduced from 67 to $50 \%$ correct. These results indicate that there is good reason to expect GMM results based on the morphology of uncharred grain to be robust to the effects of charring.

\section{An Old Landrace to Test Archaeobotanical Geometric Morphometrics}

To determine the ability of GMM to recognise landraces in the archaeological record, testing using present-day landraces is required. An ideal candidate is bere (pronounced bear), a six-row hulled barley landrace once widely grown in Scotland. Whilst today largely restricted to Orkney, bere has long been associated with Scotland's island groups and has genotypically distinct forms from Orkney, Shetland and the Western Isles (Southworth 2007).

Bere is thought to be one of the oldest surviving cereal landraces in Europe (Jarman 1996). This longevity may be attributed to bere's adaptation to the conditions of northern Scotland, including its suitability for short, cool growing seasons (Chappell et al. 2017) and tolerance of sandy, coastal soils which are deficient in trace elements 
(George et al. 2014), specifically manganese deficiency (Schmidt et al. in prep.). Bere is, therefore, an important genetic resource for crop breeding (Feuillet et al. 2008; Negri et al. 2009), with conservation on working farms most likely to ensure its continued availability (Green et al. 2009; Newton et al. 2011). This can be encouraged by developing high provenance food or drink markets for bere products (Martin et al. 2009), based on the landrace's historic (and, potentially, prehistoric) association with the islands.

Although the chronology of bere's introduction to northern Scotland is unknown, a Scandinavian introduction to Britain in the eighth century AD has been suggested (Jarman 1996). This is supported by many historical references in which the crop is often called bygg, the Old Norse for barley (Fenton 1978), and by the frequent use of the word bere, in Old English, for barley (Cameron et al. 2016). More recent evidence for bere comes from the usage of the terms 'bere' and 'beare' for a type of British sixrow barley in historical literature dating back to the sixteenth century AD (Jarman 1996; Neilson 2016). Such sources are notoriously difficult to interpret, however, as naming conventions change over time. Today, the name 'bere' is restricted to the particular landrace grown in northern Scotland but this may not have always been the case historically. The uncertainties of bere's heritage can be better addressed by the identification of the landrace in the archaeological record.

Bere's long history of use in northern Scotland presents an ideal opportunity to test the ability of GMM to differentiate it from other landraces. In order to be relevant for archaeological research, analysis is restricted to shape information of grains (as other characteristics, such as veining or colour, rarely preserve archaeologically). The research presented here goes further than previous studies (Ros et al. 2014; Bonhomme et al. 2017) as it attempts to identify a specific landrace relevant to the archaeological record, and also investigates the influence of growing conditions on grain shape. Specifically, we will determine whether bere can be differentiated from similar barley landraces by grain shape alone and despite differences in growing conditions, between two locations, and the effects of charring.

\section{Materials and Methods}

\section{Growth Trials}

A series of hulled barleys were grown in two trials, one at Orkney College, Kirkwall $\left(58^{\circ} 59^{\prime} \mathrm{N}\right.$ and $\left.2^{\circ} 56^{\prime} \mathrm{W}\right)$, and the other at the James Hutton Institute $\left(56^{\circ} 29^{\prime} \mathrm{N}\right.$ and $3^{\circ}$ $7^{\prime} \mathrm{W}$ ) near Dundee. These barleys were represented by 54 accessions (each a specific example of a landrace sourced from a gene bank) grouped in the following categories: bere barley (six-row) of Orkney and Western Isles provenance, Scandinavian landraces (six-row), non-bere Scottish landraces (two-row) and non-Scottish British landraces (two-row) (Table S1). The soil at both sites was a clay loam. Each accession was planted in a single, individual plot $(2 \times 1 \mathrm{~m})$ at a seed rate giving 365 plants $\mathrm{m}^{-2}$.

Trials were sown at Orkney and Dundee on 21 April and 14 March 2016, respectively, and the inputs applied are detailed in Table S2. During most of the cropping season, conditions at Orkney were cooler and wetter (March to August 2016: mean temperature $10.3{ }^{\circ} \mathrm{C}$ vs. $11.2{ }^{\circ} \mathrm{C}$; total rainfall $367 \mathrm{~mm}$ vs. $327 \mathrm{~mm}$; Table S3). At 
Orkney, barley was harvested between 16 August and 12 September, upon reaching the hard grain stage (Zadoks growth stage 92). Prior to harvest, a $60-\mathrm{cm}$ length of row was sampled and three representative spikes were selected from this sample to provide grains for morphometric analysis. Spikes were dried at $35^{\circ} \mathrm{C}$ for $24 \mathrm{~h}$. Harvesting of the Dundee trial with a small plot combine occurred on 29 August.

\section{Genotyping}

For each sample, five grains were taken for genotyping from the source used to sow each of the field trials. Seeds were germinated in Petri plates on filter paper for 5 days and DNA was extracted from young leaf material, using Qiagen DNeasy plant minipreparation kit (Qiagen, Hilden, Germany). Genotyping was undertaken using Illumina GoldenGate BeadArray technology with the BOPA1 and 2 single nucleotide polymorphism (SNP) sets (Close et al. 2009). Genotype data were processed and manually inspected using the BeadStudio 3.1.3.0 software package (Illumina Inc., San Diego, California, USA). Of the 3072 BOPA SNPs, 2312 were reliably called in at least $95 \%$ of the individuals and used in the analysis (Table S4). A simple cluster analysis using PAST 1.91 software suite (Hammer et al. 2001) based on Hamming's distance (=1 simple matching) was undertaken, as was principal coordinate analysis (PCoA).

\section{Morphometrics}

Barley was available as whole ears from Orkney and as free grain from Dundee. For the Orkney material, grains were removed individually from the ears with only central (untwisted) grains selected from along the ears. Only central grains were included so as to exclude differences in grain shape due to the degree of twisting in lateral grains, and to provide equivalent plant parts from six-row and two-row barley samples. Tail grains exhibiting stunted growth (e.g. Hillman 1984) and grains with any other obvious malformation were avoided because these atypically shaped grains would generate excess variation in the GMM analysis, and they can be excluded also from archaeological samples. Grains from Dundee were selected at random avoiding tail, malformed and visibly twisted grains. At least five grains were selected per accession.

Hulls and embryo protrusions, obscuring the grain outline, were removed with forceps. The dorsal plane of grains was photographed using a Leica DFC450 camera attached to a Leica M205 APO microscope. Photographed grains were outlined using Adobe ${ }^{\circledR}$ Photoshop ${ }^{\circledR}$ and converted to binary masks. Landmarks were added to the embryo-end tip and apical-end tip using ImageJ (Schneider et al. 2012). Binary (blackand-white) masks and landmarks coordinates were imported to the $\mathrm{R}$ environment version 3.4.2. ( $\mathrm{R}$ Core Team 2017) and the package Momocs version 1.2.1. (Bonhomme et al. 2014) was used for morphometric analysis.

Size and orientation were excluded by Bookstein alignment using the two landmarks, and outlines were centred and scaled. Elliptical Fourier representations were calculated for the first five harmonics (sufficient to gather 95\% harmonic power; Bonhomme et al. 2014: 14). Twenty quantitative variables were generated, of which 13 were non-normally distributed (i.e. Shapiro-Wilks test $p$ value $\leq 0.05$ ) and the variance between barley groups for 15 was uneven (i.e. Levene's test $p$ value $\leq 0.05$ ). All variables were analysed using multivariate statistical approaches (Venables and 
Ripley 2002), including principal components analysis (PCA) and linear discriminant analysis (LDA). LDA was chosen as the primary basis of analysis because LDA, as a supervised classification tool, seeks out the most diagnostic variable combination to separate known groups rather than simply the largest source of variation, as is the case for unsupervised procedures, and is thus appropriate for establishing the diagnostic capabilities of GMM for landrace recognition. Non-normality and uneven variance between groups are sub-optimal for LDA, and whilst LDA results are expected to be reliable (not spurious), they are potentially not as strong as those where optimal conditions are met. The significance of the group separations was further tested by multivariate analysis of variance (MANOVA).

\section{Experimental Charring}

Three accessions each of bere and Scandinavian landraces were selected randomly for further morphometric analysis, including charring experiments. Sixty grains (10 per accession) were charred individually, permitting one-to-one comparison pre- and postcharring. Grains were buried in sand, to achieve reducing conditions, and placed in an oven set to $230{ }^{\circ} \mathrm{C}$ for $6 \mathrm{~h}\left( \pm<1{ }^{\circ} \mathrm{C}\right.$ accuracy). This charring protocol is designed to produce material representative of well-preserved archaeobotanical material, as discussed elsewhere (Fraser et al. 2013; Charles et al. 2015; Bonhomme et al. 2017).

\section{Results}

\section{Genotyping Indicates Three Barley Clusters}

Fifty-four accessions which represent both two- and six-row barleys grown across the UK and Scandinavia during the last hundred years, along with bere barleys from Orkney and the Western Isles were genotyped with 3072 mapped genetic markers (BOPA1\&2, Close et al. 2009). For four six-row accessions (three bere and one Scandinavian landrace) SNP data were anomalous, contradicting accession information and, as this casts doubt on the provenance of these accessions, they have been excluded from further analysis (Table S1).

SNP data shows three clusters (Fig. 1a and Fig. S1): (i) all two-row accessions including those with a Scottish and non-Scottish British origin, (ii) Scandinavian accessions plus two with a presumed Scandinavian origin and (iii) a tight cluster of all bere accessions plus the Faroese barley. Within the bere, there is separation between accessions with an Orkney provenance and those with a Western Isles provenance (Fig. 1b).

\section{Grain Geometric Morphometrics Distinguishes Barley Landraces}

A total of 565 grains from all 54 accessions (Table S1) were included in GMM analysis. The GMM data were noisier than the SNP data (for a discussion of intra- and inter-ear variation see SI), though LDA shows these accessions separate into groups with similar membership to those based on SNP data (Fig. 2). The overall LOO reclassification rate is low, $61.5 \%$, but the misclassifications are informative in identifying morphologically 


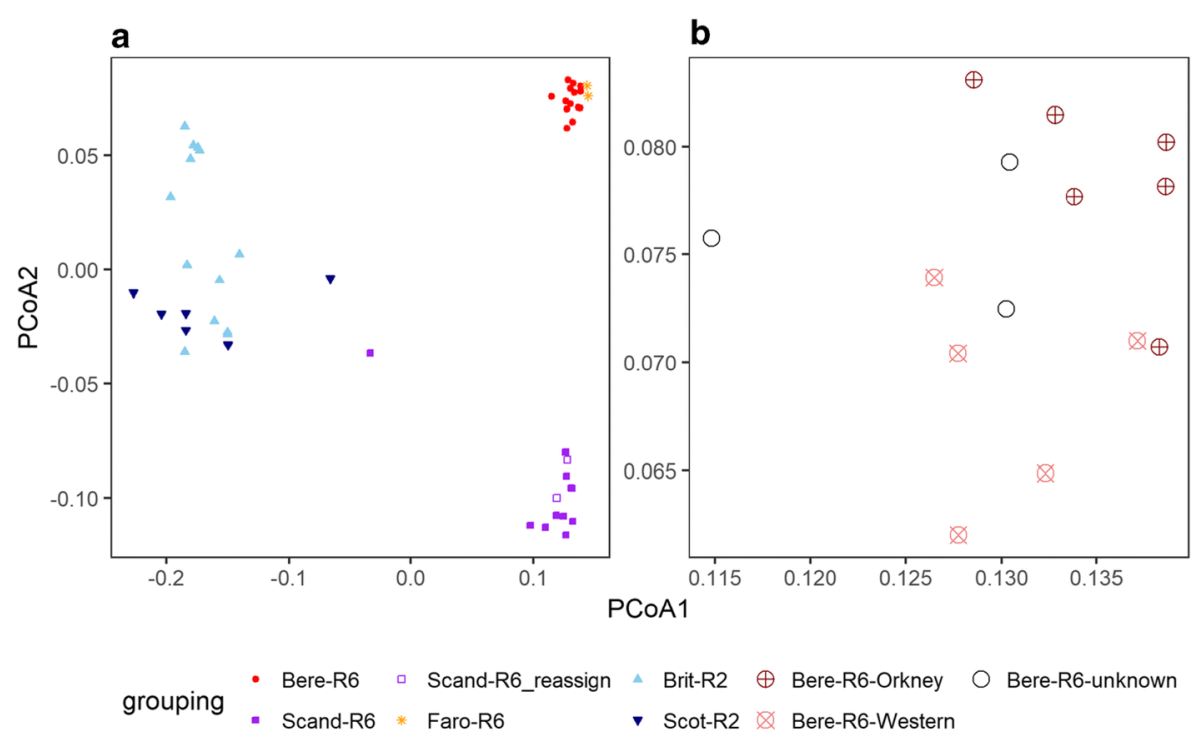

Fig. 1 Principal coordinate analysis (PCoA1 and PCoA2) of SNP data for the 50 barley accessions that were reliably genotyped. a All 50 non-anomalous accessions. b Non-anomalous bere accessions only. Symbols (and colours) denote barley group: a Circle (red)_six-row bere; filled square (purple)—six-row Scandinavian; open square (purple) _ presumed six-row Scandinavian; upward triangle (light blue) - two-row non-Scottish British; downward triangle (dark blue) - two-row Scottish; star (orange)-six-row Faroese; b Circle with plus sign (dark red) - six-row bere of Orkney provenance; circle with multiplication sign (light red) six-row bere of Western Isles provenance; open circle (black)_-six-row bere of unknown provenance

similar groups of grains (Table 1). Two-row grains tend to group together, with most classified as either non-Scottish British or Scottish British two-row landraces. Scandinavian grains, including those of presumed Scandinavian origin, group together, and most are classified as Scandinavian. The few Faroese grains tend to group with the bere, with most of the bere and Faroese grains classified as bere. Grains from the four six-row accessions with an uncertain origin overlap the six-row groups (Fig. 2a), which is consistent with the genotype data.

An LDA based on groupings following the SNP data (for the 50 accessions - 525 grains - with reliable results, Table S1) has a high LOO reclassification rate of $81.7 \%$ (Fig. 2b and Table S5) and MANOVA indicates that the difference between groups is significant (Pillai $=1.04625, F=14.5658, p<0.001$ ). Reclassification can be improved further, to $86.9 \%$, by calculating average shapes for each accession per trial location prior to LDA (Fig. S2 and Table S6).

The greatest distinction in grain morphology is for row type (LDA, LOO reclassification $=87.6 \%$; MANOVA, Pillai $=0.56552, F=35.404, p<0.001)$, with reclassification slightly better for the Orkney-grown material $(92.7 \%$, Fig. 3a) than for the Dundee-grown (83.4\%, Fig. 3b). Taking the six-row grains in isolation, the bere plus Faroese group is distinguished from Scandinavian landraces (LDA, LOO reclassification $=85.1 \%$; MANOVA, Pillai $=0.53747, F=17.081, p<0.001$ ), and the difference is again more pronounced for the Orkney-grown material $(90.9 \%$ vs. $80.7 \%$, Fig. 3c, d).

As was the case for SNP data, GMM data indicate differences between bere accessions based on their provenance. The six Orkney bere accessions (65 grain) and five Western Isles bere accessions (60 grain) can be distinguished by grain morphology 
a

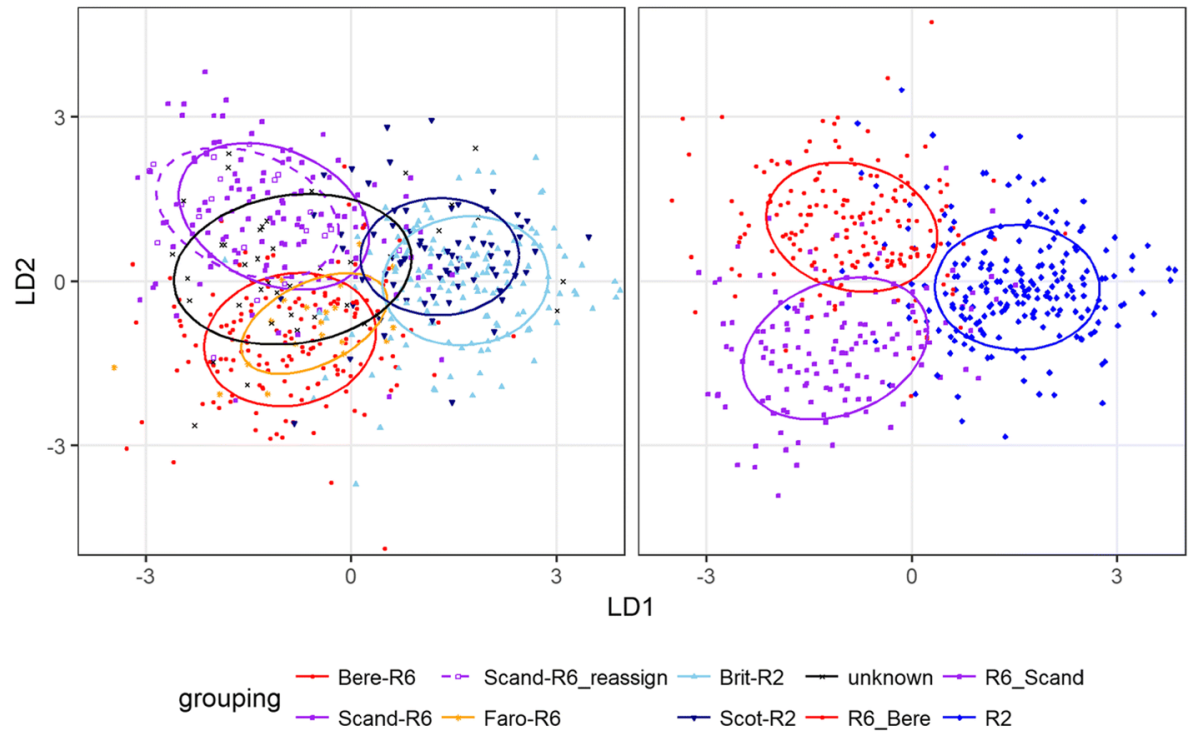

Fig. 2 Linear discriminant analysis (LD1 and LD2) of GMM data for barley grains. a 525 grains from the 50 accessions with non-anomalous SNP data, assigned according to accession information with the 20 grains from the four unknown accessions added as new data. b 525 grains from the 50 accessions with nonanomalous SNP data, assigned according to genetic cluster. Confidence ellipses set at level 0.68. Symbols (and colours and ellipse lines) denote barley group: a circle (red)_six-row bere; filled square (purple) - six-row Scandinavian; open square (purple, dashed ellipse line)_ presumed six-row Scandinavian; upward triangle (light blue) - two-row non-Scottish British; downward triangle (dark blue) - two-row Scottish; star (orange) - six-row Faroese; multiplication sign (black) — six-row unknown origin; b Circle (red) - six-row bere or Faroese; squares (purple) six-row Scandinavian including presumed Scandinavian; diamonds (blue)-two-row British

$($ LDA, LOO reclassification $=81.6 \%$; MANOVA, Pillai $=0.61352, F=8.2548$, $p<0.001)$, and in this case there is little difference between the Orkney-grown and Dundee-grown material ( $82.1 \%$ vs. $83.6 \%$, Fig. 3e, f).

The actual difference in the shape of grains is not easily observed by eye. Through shape amplification, however, it is possible to visualise the average differences in grains for the barley groups (Fig. 4). Shape differences between two-row and six-row central grains appear to be related to the overall roundness and the broadness of the embryo end relative to the apical end (Fig. 4a). Amongst the six-row grains, bere differs from Scandinavian landraces in that Scandinavian grains exhibit a 'tucking-in' along the lateral edge near either end of the grain, whereas the bere usually has a continuous gentle curve from the mid-point to the ends (Fig. 4b). Bere of Orkney and Western Isles provenances (Fig. 4c) are both rounded, with Western Isles bere grains broader relative to their overall length.

\section{Charring Has a Consistent and Modest Effect on Barley Grain Shape}

In their uncharred state, LDA on the subset of 60 grains selected for experimental charring correctly assigns 95\% (57 of 60) as bere or Scandinavian (Table S7). 
Table 1 Linear discriminant analysis LOO reclassification results (grain count and proportion of total grains per group) for GMM data of grains for all accessions assigned by accession information. Group names are abbreviated as follows: Bere-R6, six-row bere; Faro-R6, six-row Faroese; Scand-R6, six-row Scandinavian; ?Scand-R6, presumed six-row Scandinavian; Brit-R2, two-row non-Scottish British; Scot-R2, two-row Scottish

\begin{tabular}{|c|c|c|c|c|c|c|}
\hline Actual & Bere-R6 & Faro-R6 & Scand-R6 & ?Scand-R6 & Brit-R2 & Scot-R2 \\
\hline \multirow[t]{2}{*}{ Bere-R6 } & 124 & 3 & 13 & 2 & 12 & 1 \\
\hline & $80 \%$ & $2 \%$ & $8 \%$ & $1 \%$ & $8 \%$ & $1 \%$ \\
\hline \multirow[t]{2}{*}{ Faro-R6 } & 16 & 0 & 1 & 0 & 1 & 2 \\
\hline & $80 \%$ & $0 \%$ & $5 \%$ & $0 \%$ & $5 \%$ & $10 \%$ \\
\hline \multirow[t]{2}{*}{ Scand-R6 } & 16 & 0 & 85 & 2 & 13 & 4 \\
\hline & $13 \%$ & $0 \%$ & $71 \%$ & $2 \%$ & $11 \%$ & $3 \%$ \\
\hline \multirow[t]{2}{*}{ ?Scand-R6 } & 3 & 0 & 16 & 0 & 0 & 1 \\
\hline & $15 \%$ & $0 \%$ & $80 \%$ & $0 \%$ & $0 \%$ & $5 \%$ \\
\hline \multirow[t]{2}{*}{ Brit-R2 } & 11 & 0 & 3 & 0 & 103 & 23 \\
\hline & $8 \%$ & $0 \%$ & $2 \%$ & $0 \%$ & $74 \%$ & $16 \%$ \\
\hline \multirow[t]{2}{*}{ Scot-R2 } & 4 & 2 & 9 & 0 & 44 & 11 \\
\hline & $6 \%$ & $3 \%$ & $13 \%$ & $0 \%$ & $63 \%$ & $16 \%$ \\
\hline
\end{tabular}

Following charring, LDA reclassifies $80 \%$ (48 of 60) correctly (Table S8). The consistency of the charring effect was assessed by comparing the PC1 scores for the subset of 60 uncharred grains with the PC1 scores for the same 60 grains in their charred state (Fig. 5). Note that PC1 accounts for $62 \%$ of the variation, and so serves as a good single-variable summary of grain shape, and that the scores of the charred grains were calculated using the loading matrix of eigenvectors obtained in the PCA of uncharred grain. There is strong correlation between the two PC1 scores $\left(r_{\text {adj }}^{2}=0.76\right.$, $p=<0.001$ ), indicating that differences in shape before and after charring are similar for all grains. There is some variation between accessions (Fig. S3), suggesting some grains may be effected slightly differently by charring. Nevertheless, taking the results as a whole, the charring effect is largely consistent between grains and is sufficiently modest as to not mask differences in grain shape between the tested landraces (Fig. S4).

\section{Discussion}

\section{Geometric Morphometrics Patterns Are Robust Across Trial Locations}

GMM distinguishes both barley row type and several landrace groups based on grain morphology and, importantly, this has been accomplished for material grown at two trial locations under different growing conditions. The implication is that the primary determinant of grain morphology is genetic, and that effects on grain morphology due to environmental conditions do not mask this. Grain morphology was effected, however, to some extent by trial location, with typically higher LDA reclassification rates for Orkney-grown material. 


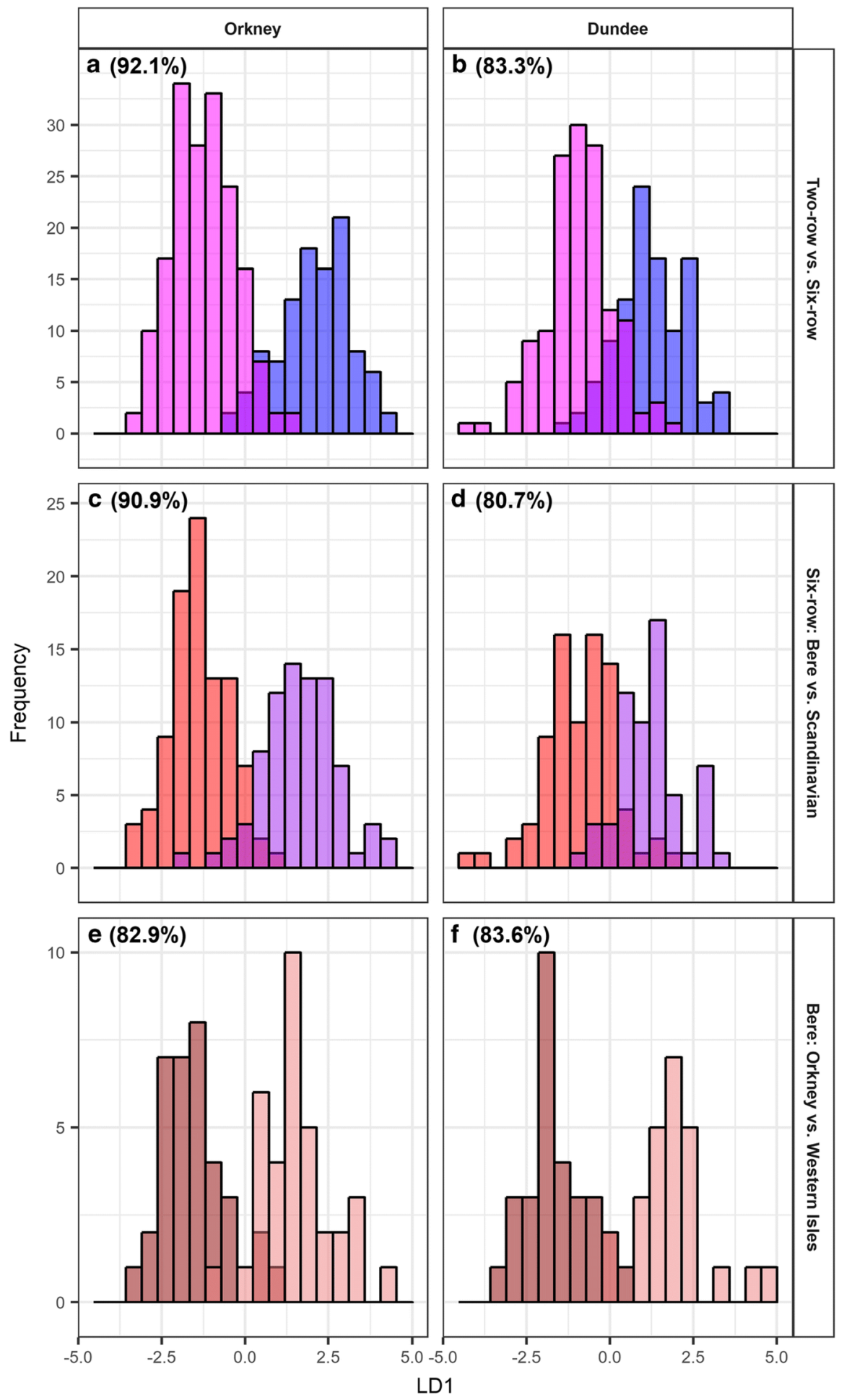


Fig. 3 Separate linear discriminant analyses (LD1) conducted for Orkney-grown and Dundee-grown barley. Percentages refer to the correct LOO reclassification rate for each LDA. a Orkney-grown grains assigned by row type - two-row (105 grains, blue) or six-row (175 grains, pink). b Dundee-grown grains assigned by row type - two-row (105 grain, blue) or six-row (140 grains, pink). c Orkney-grown six-row grains assigned by genetic cluster - bere or Faroese (95 grains, red) or Scandinavian including presumed Scandinavian (80 grains, purple). d Dundee-grown six-row grains assigned by genetic cluster-bere or Faroese (80 grains, red) or Scandinavian including presumed Scandinavian (60 grains, purple). e Orkney-grown bere grains assigned by provenance - Orkney (35 grains, dark red) or Western Isles (35 grains, light red). f Orkney-grown bere grains assigned by origin - Orkney (30 grains, dark red) or Western Isles ( 25 grains, light red)

The reason for superior reclassification rates, and therefore more distinctive grain morphologies, for Orkney-grown material is unknown. The possible accidental inclusion of twisted grains (i.e. those from the lateral spikelet position in six-row barley) for the Dundee material (see Materials and Methods) may explain the pattern. Alternatively, differences in growing conditions at the two trial sites may have had an influence. Growing conditions can be predicted to most likely affect grain morphology during the
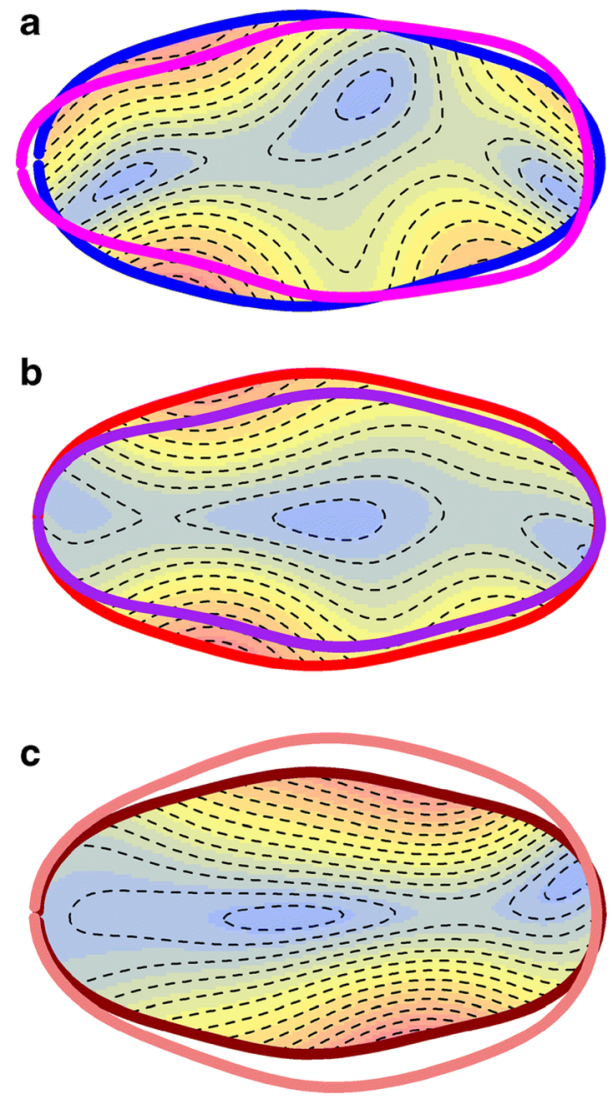

Fig. 4 Amplified $(\times 2)$ isometric thin plate splines comparing mean grain shape for different barley groups. Dorsal view of grains with embryo end to the left. Fill colours and contour lines indicate similarity with overlaying shape: reddish areas with tight contours indicate large differences, and blueish areas with wide contours indicate similarity. Border colour indicates barley group. a Two-row (210 grains, blue) or six-row (355 grains, pink). b Bere (155 grains, red) and Scandinavian (120 grains, purple). c Orkney bere (65 grains, dark red) and Western Isles bere (60 grains, light red) 


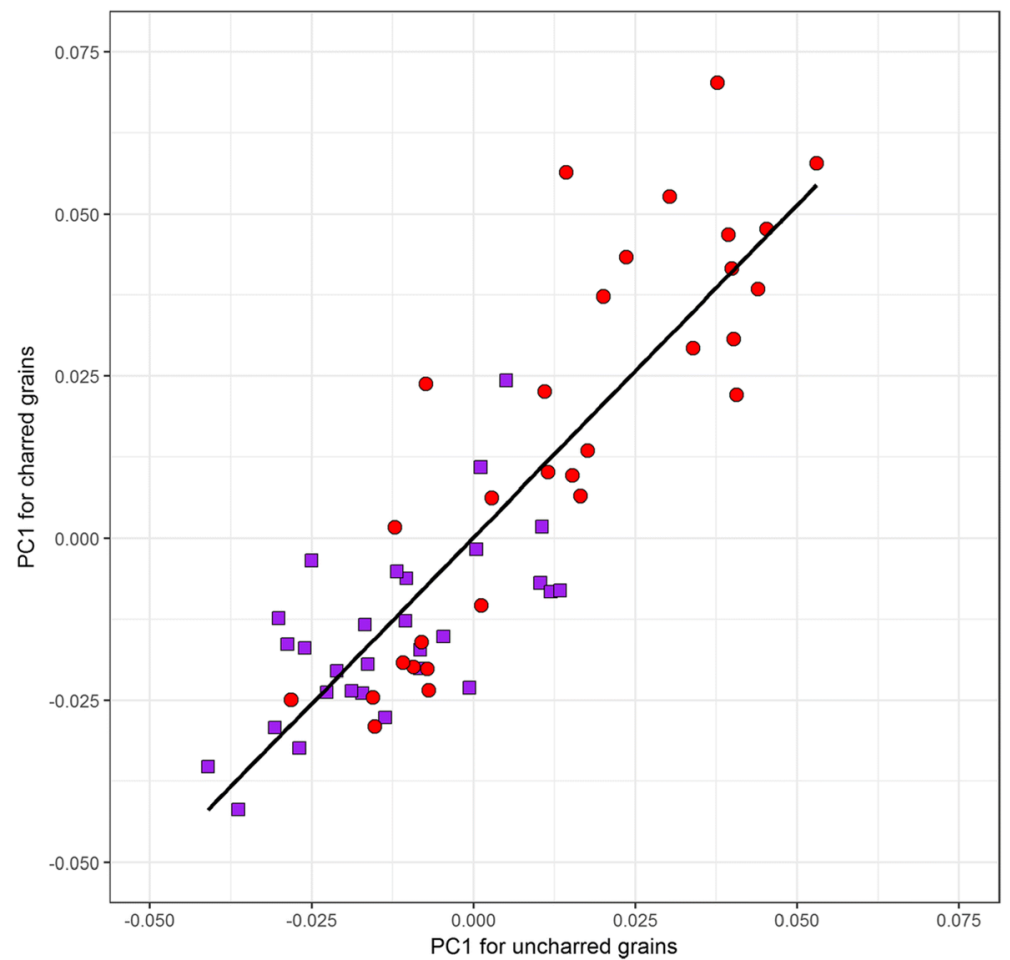

Fig. 5 Principal component 1 scores for subset of 60 uncharred grains plotted against the principal component 1 scores for the same 60 grains in their charred state calculated using the loading matrix of eigenvalues obtained from the PCA of uncharred grains. The linear regression (black) shown was calculated on all grains, $r_{\text {adj }}^{2}=0.76$, including the 30 bere grains (red circles) and 30 Scandinavian grains (purple squares)

grain formation period (Zadok's stages 71-87), which relates to approximately the end of July and start of August for these trials. During this period, the Dundee site experienced about one-third less rainfall and was slightly warmer (Table S3), and this might have resulted in differences in grain formation. Finally, it might be hypothesised that landraces are most distinctive when grown in the conditions to which they are adapted, which in this case applies only to the Orkney-grown bere. Orkney bere, however, was less readily distinguished from Western Isles bere on Orkney, casting doubt on this theory. Based on our experiment involving two trial locations, the relationship between growing conditions and grain morphology appears minor, at least compared to the genetic determination of grain morphology, and should be considered neutral until demonstrated otherwise.

\section{Grain Geometric Morphometrics Distinguishes Barley Row Type}

GMM was most effective at distinguishing two-row and six-row barley grains based only on straight grains (i.e. visibly twisted grains from the lateral position in six-row barley were excluded). This finding supports previous work (Ros et al. 2014) in which similar LDA reclassification to row for 300 barley grains was $91 \%$ correct, but also extends it by demonstrating that the differentiation of two-row and six-row grains does 
not rely on the presence of twisted grains in the latter. The inclusion in this study of two trial locations strengthens the case for archaeological relevance. The ability of GMM to determine row type for individual grains permits an objective and probabilistic approach to row classification that can be extended to small assemblages or samples, for which the traditional ratio-based approach would be unreliable.

\section{Grain Geometric Morphometrics Distinguishes Barley Landraces}

Going beyond the kinds of identifications possible using traditional archaeobotany, the results of this study demonstrate that GMM can characterise the grain morphology of some specific groups of landraces, providing a novel archaeological method for exploring the spread and use of landraces. Neither SNP nor GMM data could distinguish between all landrace groups. The lack of genetic or morphometric difference in two-row grains from Scotland and the rest of Britain may indicate that local differences in landrace naming conventions may not readily translate to biological differences. Indeed, the groups that were genetically and morphologically distinct-Scandinavian landraces, Orkney bere and Western Isles bere - are isolated from each other by sea. Sea barriers reduce the likelihood of outbreeding between landraces and, thus, increase genetic isolation and population divergence (e.g. Hagenblad et al. 2017). It is thus expected that distinctive grain morphology will be most pronounced for island populations. The apparent contradiction of this by the Faroese landraces is discussed in the supplementary information.

Despite the centrality of genetics to grain morphology, it is to be expected that the phenotypic and genotypic uniqueness of landraces will not always manifest as a uniqueness in grain shape. Grain morphology should not, therefore, be considered a proxy for genetic analysis. Rather, archaeobotanical GMM must be considered a tool for detecting landraces that have distinct grain morphology regardless of their phenotypic or genotypic character. Nevertheless, whilst it cannot be expected that the genotypic data will always map onto the morphometric data, it is clear, at least in the case of bere, that genotypically distinct types of the landrace can also be morphologically distinct. Given the limitations of extracting aDNA from charred remains and the necessity of studying the archaeological record in order to establish the rise and fall of bere and other landraces, our morphometric findings are essential for further study of past landrace use and ancestry.

\section{Bere's Past, and the Future of Archaeological Landrace Recognition}

This novel GMM approach to recognising bere barley provides the means to explore the origins and past usage of this landrace through the archaeological record. The distinctiveness of bere from present-day Scandinavian landraces casts doubt on the Viking introduction theory. This leaves three possibilities: (1) bere derived from landraces of mainland Britain; (2) bere derived from extinct/unavailable landraces from Scandinavia; or (3) bere evolved on the Scottish islands from an earlier introduction. These origins can only be tested by studying the morphology of barley grains in the archaeological record of the Scottish islands, and through comparison with contemporary and archaeological barley from mainland Britain, Scandinavia and other areas. 
The availability of present-day specimens of bere makes it an ideal candidate for exploring the potential of our GMM approach, but the applications of the method are not limited to the study of bere. By studying present-day landraces, it is also possible to determine the scope of grain morphologies represented, and identify distinctive forms. The archaeological record, however, is likely to contain landraces for which no parallel survives today - including potential 'lost crops' (Fuller et al. 2012). Analysis of archaeological grains, therefore, must not be restricted to only matching archaeological specimens to modern grain morphologies. An advantage of the GMM approach in this regard is that results are probabilistic, and it is therefore relatively straightforward to identify grains that are a poor match to any of the landraces included in present-day training data.

The application of GMM approaches to the archaeobotanical record relies on its suitability for use on charred plant remains, which account for much of the record. The results of our charring experiments corroborate those conducted by others (Bonhomme et al. 2017; Ros et al. 2014), indicating that the effect on grain shape is modest in its magnitude and predictable in terms of the manner of shape change. This consistency provides the opportunity for a 'correction factor' to be developed that infers uncharred shapes from charred grains, and so permitting the direct comparison with present-day barley.

Application of GMM approaches to the archaeobotanical record will, however, still pose challenges. Landrace recognition, as opposed to the identification of row type for which the distinction is clearer, will benefit from large sample sizes and the targeting of well-preserved grains that lack gross, charring-induced distortions (Charles et al. 2015). In addition, stable isotope analysis provides information on crop growing conditions and husbandry practices (Bogaard et al. 2013; Wallace et al. 2013, 2015; Bogaard et al. 2016; Styring et al. 2016; Fiorentino et al. 2015) which, if used in tandem with GMM, will provide a detailed picture of ancient crop use.

\section{Conclusion}

This study of present-day specimens of bere, one of Europe's oldest surviving barley landraces, and comparison with similar barley landraces has demonstrated the potential of geometric modern morphometric (GMM) analysis of grain to contribute to archaeological research questions through the novel recognition of landraces. Although not all landraces may be detected through GMM analysis, those with distinctive grain morphology can be statistically distinguished from others. The results presented here and elsewhere indicate that sources of uncertainty (e.g. growing conditions, charring, inherent variability) can be overcome, providing the opportunity to use GMM to reach archaeologically invisible landrace-level identifications.

The importance of below species-level identification of archaeological plant remains has been highlighted by previous studies of fruit crops. Now, archaeobotanical GMM can be extended to cereal crops, the primary source of calories in large parts of the world throughout much of history and prehistory. The recognition of landraces will permit the emergence of locally adapted crop forms to be identified and their spread and exchange between farming communities to be charted, which in turn informs on past economies and cultural identity. For bere, its recognition in the archaeological record will contribute to understanding the origins and history of this important heritage resource, helping in turn to secure its long-term future. 
Acknowledgements The roots of this research, and the connections between the authors, were established during the ERC projects Evolutionary Origins of Agriculture (PI: Prof. G. Jones, University of Sheffield, 269830-EOA) and ADAPT: Life in a Cold Climate (PI: Prof. T. Brown, University of Manchester, 339941EOA). We thank both of PIs for their continued support, and inspiration to push the boundaries of science-based archaeology. Collaboration between the interdisciplinary team of authors was crystallised at a knowledge exchange event based around bere barley in June 2017, hosted by Orkney College of the University of the Highlands and Islands. We thank the college, and all those that attended and supported that event. Finally we would like to thank Prof. Caroline Jackson, University of Sheffield, and three anonymous reviewers for constructive feedback on the manuscript.

Funding Information This research was made possible by an alumni donation to the University of Sheffield to which the first author was the recipient.

Publisher's Note Springer Nature remains neutral with regard to jurisdictional claims in published maps and institutional affiliations.

Open Access This article is distributed under the terms of the Creative Commons Attribution 4.0 International License (http://creativecommons.org/licenses/by/4.0/), which permits unrestricted use, distribution, and reproduction in any medium, provided you give appropriate credit to the original author(s) and the source, provide a link to the Creative Commons license, and indicate if changes were made.

\section{References}

Adams, D. C., Rohlf, F. J., \& Slice, D. E. (2004). Geometric morphometrics: ten years of progress following the 'revolution'. Italian Journal of Zoology, 71(1), 5-16. https://doi.org/10.1080/11250000409356545.

Bocquet-Appel, J.-P., Naji, S., Linden, M. V., \& Kozlowski, J. K. (2009). Detection of diffusion and contact zones of early farming in Europe from the space-time distribution of $14 \mathrm{C}$ dates. Journal of Archaeological Science, 36(3), 807-820. https://doi.org/10.1016/j.jas.2008.11.004.

Bogaard, A., Fraser, R., Heaton, T. H. E., Wallace, M., Vaiglova, P., Charles, M., et al. (2013). Crop manuring and intensive land management by Europe's first farmers. Proceedings of the National Academy of Sciences, $110(31), 12589-12594$.

Bogaard, A., Hodgson, J., Nitsch, E., Jones, G., Styring, A., Diffey, C., et al. (2016). Combining functional weed ecology and crop stable isotope ratios to identify cultivation intensity: a comparison of cereal production regimes in Haute Provence, France and Asturias, Spain. Vegetation History and Archaeobotany, 25(1), 57-73. https://doi.org/10.1007/s00334-015-0524-0.

Bogucki, P. (2000). How agriculture came to north central Europe. In T. D. Price (Ed.), Europe's first farmers (pp. 197-218). Cambridge: Cambridge University Press.

Bonhomme, V., Picq, S., Gaucherel, C., \& Claude, J. (2014). Momocs: outline analysis using R. Journal of Statistical Software, 56(13), 1-24.

Bonhomme, V., Forster, E., Wallace, M., Stillman, E., Charles, M., \& Jones, G. (2017). Identification of interand intra-species variation in cereal grains through geometric morphometric analysis, and its resilience under experimental charring. Journal of Archaeological Science, 86(Supplement C), 60-67. https://doi. org/10.1016/j.jas.2017.09.010.

Bonsall, C., Anderson, D., \& Macklin, M. (2002). The Mesolithic-Neolithic transition in western Scotland and its European context. Documenta Praehistorica, 29, 1-25.

Bouby, L., Figueiral, I., Bouchette, A., Rovira, N., Ivorra, S., Lacombe, T., et al. (2013). Bioarchaeological insights into the process of domestication of grapevine (Vitis vinifera L.) during Roman Times in Southern France. PLoS One, 8(5), e63195. https://doi.org/10.1371/journal.pone.0063195.

Brown, T. A., Cappellini, E., Kistler, L., Lister, D. L., Oliveira, H. R., Wales, N., et al. (2015). Recent advances in ancient DNA research and their implications for archaeobotany. Vegetation History and Archaeobotany, 24(1), 207-214. https://doi.org/10.1007/s00334-014-0489-4.

Bunning, S. L., Jones, G., \& Brown, T. A. (2012). Next generation sequencing of DNA in 3300-year-old charred cereal grains. Journal of Archaeological Science, 39(8), 2780-2784. https://doi.org/10.1016/j. jas.2012.04.012.

Burger, P., Terral, J.-F., Ruas, M.-P., Ivorra, S., \& Picq, S. (2011). Assessing past agrobiodiversity of Prunus avium L. (Rosaceae): a morphometric approach focussed on the stones from the archaeological site Hôtel- 
Dieu (16th century, Tours, France). Vegetation History and Archaeobotany, 20(5), 447. https://doi. org/10.1007/s00334-011-0310-6.

Camacho Villa, T. S., Maxted, N., Scholten, M., \& Ford-Lloyd, B. (2006). Defining and identifying crop landraces. Plant Genetic Resources, 3, 373-384.

Cameron, A., Amos, A. C., \& Healey, A. d. P. (Eds.). (2016). Dictionary of Old English: A to H online. Toronto: Dictionary of Old English Project.

Chappell, A., Scott, K. P., Griffiths, I. A., Cowan, A. A., Hawes, C., Wishart, J., et al. (2017). The agronomic performance and nutritional content of oat and barley varieties grown in a northern maritime environment depends on variety and growing conditions. Journal of Cereal Science, 74, 1-10. https://doi.org/10.1016 /j.jcs.2017.01.005.

Charles, M., Forster, E., Wallace, M., \& Jones, G. (2015). "Nor ever lightning char thy grain"1: establishing archaeologically relevant charring conditions and their effect on glume wheat grain morphology. STAR: Science \& Technology of Archaeological Research, 1(1), 1-6. https://doi.org/10.1179/2054892315 Y.0000000008.

Close, T. J., Bhat, P. R., Lonardi, S., Wu, Y., Rostoks, N., Ramsay, L., et al. (2009). Development and implementation of high-throughput SNP genotyping in barley. BMC Genomics, 10(1), 582. https://doi. org/10.1186/1471-2164-10-582.

Cope, J. S., Corney, D., Clark, J. Y., Remagnino, P., \& Wilkin, P. (2012). Plant species identification using digital morphometrics: a review. Expert Systems with Applications, 39(8), 7562-7573. https://doi. org/10.1016/j.eswa.2012.01.073.

Fenton, A. (1978). The Northern Isles: Orkney and Shetland. Easth Lothian: Tuckwell Press.

Feuillet, C., Langridge, P., \& Waugh, R. (2008). Cereal breeding takes a walk on the wild side. Trends in Genetics, 24, 24-32.

Fiorentino, G., Ferrio, J. P., Bogaard, A., Araus, J. L., \& Riehl, S. (2015). Stable isotopes in archaeobotanical research. [journal article]. Vegetation History and Archaeobotany, 24(1), 215-227. https://doi.org/10.1007 /s00334-014-0492-9.

Fort, J. (2015). Demic and cultural diffusion propagated the Neolithic transition across different regions of Europe. [article]. Journal of the Royal Society Interface, 12(106). https://doi.org/10.1098/rsif.2015.0166.

Fraser, R., Styring, A., Wallace, M., Bogaard, A., Jones, G., Charles, M., et al. (2013). Assessing the effects of charring, burial, ABA pre-treatment and natural variation in the stable carbon and nitrogen isotope values of archaeobotanical crop remains. Journal of Archaeological Science, 40, 4753-4766.

Fuller, D. Q., Willcox, G., \& Allaby, R. G. (2012). Early agricultural pathways: moving outside the 'core area' hypothesis in Southwest Asia. Journal of Experimental Botany, 63(2), 617-633. https://doi.org/10.1093 /jxb/err307.

George, T. S., French, A. S., Brown, L. K., Karley, A. J., White, P. J., Ramsay, L., et al. (2014). Genotypic variation in the ability of landraces and commercial cereal varieties to avoid manganese deficiency in soils with limited manganese availability: is there a role for root-exuded phytases? Physiologia Plantarum, 151(3), 243-256. https://doi.org/10.1111/ppl.12151.

Green, N., Campbell, G., Tulloch, R., \& Scholten, M. (2009). Scottish landrace protection scheme. In M. Veteläinen, V. Negri, \& N. Maxted (Eds.), European landraces: on-farm conservation, management and use (pp. 233-243). Rome: Bioversity International.

Hagenblad, J., Morales, J., Leino, M. W., \& Rodríguez-Rodríguez, A. C. (2017). Farmer fidelity in the Canary Islands revealed by ancient DNA from prehistoric seeds. Journal of Archaeological Science, 78, 78-87. https://doi.org/10.1016/j.jas.2016.12.001.

Halstead, P. (1989). Like rising damp? An ecological apporach to the spread of farming in south east and central Europe. In A. Milles, D. Williams, \& N. Gardner (Eds.), The beginnings of agriculture, vol. International Series 196 (pp. 23-53). Oxford: B.A.R.

Hammer, Ø., Harper, D. A. T., \& Ryan, P. D. (2001). PAST: paleontological statistics software package for education and data analysis. Palaeontologia Electronica, 4(1), 1-9.

Hillman, G. (1984). Interpretation of archaeological plant remains: the application of ethnographic models from Turkey. In W. V. Zeist \& W. A. Casparie (Eds.), Plants and ancient man (pp. 1-41, Studies in palaeoethnobotany). Rotterdam: A.A. Balkema.

Jacomet, S., \& Kreuz, A. (1999). Archäobotanik. Aufgaben, Methoden und Ergebnisse vegetations- und agrargeschichtlicher Forschung. Stuttgart: Ulmer.

Jarman, R. (1996). Bere barley - a living link with 8th century? Plant Varieties and Seeds, 9, 191-196.

Jones, G., Jones, H., Charles, M. P., Jones, M. K., Colledge, S., Leigh, F. J., et al. (2012). Phylogeographic analysis of barley DNA as evidence for the spread of Neolithic agriculture through Europe. Journal of Archaeological Science, 39(10), 3230-3238. https://doi.org/10.1016/j.jas.2012.05.014. 
Lycett, S. J., \& von Cramon-Taubadel, N. (2013). A 3D morphometric analysis of surface geometry in Levallois cores: patterns of stability and variability across regions and their implications. Journal of Archaeological Science, 40(3), 1508-1517. https://doi.org/10.1016/j.jas.2012.11.005.

Martin, P., Wishart, J., Cromarty, A., \& Chang, X. (2009). New markets and supply chains for Scottish bere barley. In M. Veteläinen, V. Negri, \& N. Maxted (Eds.), European landraces: on-farm conservation, management and use (pp. 251-263). Rome: Bioversity International.

Mascher, M., Schuenemann, V. J., Davidovich, U., Marom, N., Himmelbach, A., Hübner, S., et al. (2016). Genomic analysis of 6,000-year-old cultivated grain illuminates the domestication history of barley. Nature Genetics, 48, 1089. https://doi.org/10.1038/ng.3611https://www.nature.com/articles/ng.3611 \#supplementary-information.

Mitteroecker, P., \& Gunz, P. (2009). Advances in geometric morphometrics. Evolutionary Biology, 36(2), 235-247. https://doi.org/10.1007/s11692-009-9055-x.

Negri, V., Maxted, N., \& Veteläinen, M. (2009). European landrace conservation: an introductione. In M. Veteläinen, V. Negri, \& N. Maxted (Eds.), European landraces: on-farm conservation, management and use (pp. 1-22). Rome: Bioversity International.

Neilson, K. (2016). What's in a name? Researching the origins of bere barley in Scotland and teh potential of geometric morphometrics to identify its presence in archaeological samples. Bachelor of Arts dissertation: Department of Archaeology, University of Sheffield.

Newton, C., Terral, J.-F., \& Ivorra, S. (2006). The Egyptian olive (Olea europaea subsp. europaea) in the later first millennium $\mathrm{BC}$ : origins and history using the morphometric analysis of olive stones. Antiquity, 80(308), 405-414. https://doi.org/10.1017/S0003598X00093716.

Newton, A. C., Flavell, A. J., George, T. S., Leat, P., Mullholland, B., Ramsay, L., et al. (2011). Crops that feed the world 4. Barley: a resilient crop? Strengths and weaknesses in the context of food security. Food Security, 3(2), 141. https://doi.org/10.1007/s12571-011-0126-3.

Newton, C., Lorre, C., Sauvage, C., Ivorra, S., \& Terral, J.-F. (2014). On the origins and spread of Olea europaea L. (olive) domestication: evidence for shape variation of olive stones at Ugarit, Late Bronze Age, Syria - a window on the Mediterranean Basin and on the westward diffusion of olive varieties. Vegetation History and Archaeobotany, 23(5), 567-575. https://doi.org/10.1007/s00334-013-0412-4.

Orrù, M., Grillo, O., Lovicu, G., Venora, G., \& Bacchetta, G. (2013). Morphological characterisation of Vitis vinifera L. seeds by image analysis and comparison with archaeological remains. Vegetation History and Archaeobotany, 22(3), 231-242. https://doi.org/10.1007/s00334-012-0362-2.

Ottoni, C., Girdland Flink, L., Evin, A., Geörg, C., De Cupere, B., Van Neer, W., et al. (2013). Pig domestication and human-mediated dispersal in Western Eurasia revealed through ancient DNA and geometric morphometrics. Molecular Biology and Evolution, 30(4), 824-832. https://doi.org/10.1093 /molbev/mss261.

Pagnoux, C., Bouby, L., Ivorra, S., Petit, C., Valamoti, S.-M., Pastor, T., et al. (2015). Inferring the agrobiodiversity of Vitis vinifera L. (grapevine) in ancient Greece by comparative shape analysis of archaeological and modern seeds. Vegetation History and Archaeobotany, 24(1), 75-84. https://doi. org/10.1007/s00334-014-0482-y.

Palmer, S. A., Moore, J. D., Clapham, A. J., Rose, P., \& Allaby, R. G. (2009). Archaeogenetic evidence of ancient Nubian barley evolution from six to two-row indicates local adaptation. PLoS One, 4(7), e6301. https://doi.org/10.1371/journal.pone.0006301.

Pearsall, D. (1989). Paleoethnobotany: a handbook of procedures. San Diego: Academic Press.

Perez, S. I., Bernal, V., \& Gonzalez, P. N. (2006). Differences between sliding semi-landmark methods in geometric morphometrics, with an application to human craniofacial and dental variation. Journal of Anatomy, 208(6), 769-784. https://doi.org/10.1111/j.1469-7580.2006.00576.x.

R Core Team. (2017). R: a language and environment for statistical computing. Vienna: R Foundation for Statistical Computing.

Ros, J., Evin, A., Bouby, L., \& Ruas, M.-P. (2014). Geometric morphometric analysis of grain shape and the identification of two-rowed barley (Hordeum vulgare subsp. distichum L.) in southern France. Journal of Archaeological Science, 41, 568-575. https://doi.org/10.1016/j.jas.2013.09.015.

Schmidt, S. B., George, T. S., Brown, L. K., Booth, A., Wishart, J., Hedley, P. E., et al. (in prep.). Ancient barley landraces adapted to marginal soils demonstrate exceptional tolerance to micronutrient limitation. Annals of Botany.

Schneider, C. A., Rasband, W. S., \& Eliceiri, K. W. (2012). NIH image to ImageJ: 25 years of image analysis. Nature Methods, 9(7), 671-675. https://doi.org/10.1038/nmeth.2089.

Southworth, C.L. (2007). The use of microsatellite markers to differentiate UK barley (Hordeum vulgare) varieties and in the population genetic analysis of bere barley from the Scottish islands. Ph.D., Heriot Watt University and the Scottish Agricultural Science Agency, 
Styring, A. K., Ater, M., Hmimsa, Y., Fraser, R., Miller, H., Neef, R., et al. (2016). Disentangling the effect of farming practice from aridity on crop stable isotope values: a present-day model from Morocco and its application to early farming sites in the eastern Mediterranean. The Anthropocene Review, 3(1), 2-22. https://doi.org/10.1177/2053019616630762.

Terral, J.-F., Alonso, N., Capdevila, R. B. i., Chatti, N., Fabre, L., Fiorentino, G., et al. (2004). Historical biogeography of olive domestication (Olea europaea L.) as revealed by geometrical morphometry applied to biological and archaeological material. Journal of Biogeography, 31(1), 63-77. https://doi.org/10.1046 /j.0305-0270.2003.01019.x.

Terral, J.-F., Tabard, E., Bouby, L., Ivorra, S., Pastor, T., Figueiral, I., et al. (2010). Evolution and history of grapevine (Vitis vinifera) under domestication: new morphometric perspectives to understand seed domestication syndrome and reveal origins of ancient European cultivars. Annals of Botany, 105(3), 443-455. https://doi.org/10.1093/aob/mcp298.

Terral, J.-F., Newton, C., Ivorra, S., Gros-Balthazard, M., de Morais, C. T., Picq, S., et al. (2012). Insights into the historical biogeography of the date palm (Phoenix dactylifera L.) using geometric morphometry of modern and ancient seeds. Journal of Biogeography, 39(5), 929-941. https://doi.org/10.1111/j.13652699.2011.02649.x.

Ucchesu, M., Orrù, M., Grillo, O., Venora, G., Paglietti, G., Ardu, A., et al. (2016). Predictive method for correct identification of archaeological charred grape seeds: support for advances in knowledge of grape domestication process. PLoS One, 11(2), e0149814. https://doi.org/10.1371/journal.pone.0149814.

Venables, W. N., \& Ripley, B. D. (2002). Modern applied statistics with S (4th ed.). New York: Springer.

Wallace, M., Jones, G., Charles, M., Fraser, R., Halstead, P., Heaton, T. H. E., et al. (2013). Stable carbon isotope analysis as a direct means of inferring crop water status. World Archaeology, 45(3), 388-409.

Wallace, M., Jones, G., Charles, M., Fraser, R., Heaton, T. H. E., \& Bogaard, A. (2015). Stable carbon isotope evidence for Neolithic and Bronze Age crop water management in the Eastern Mediterranean and Southwest Asia. PLoS One, 10(6), e0127085. https://doi.org/10.1371/journal.pone.0127085.

Zelditch, M., Swiderski, D., \& Sheets, H. (2012). Geometric morphometrics for biologists: a primer. London: Academic Press.

\section{Affiliations}

\section{Wallace ${ }^{1} \cdot$ V. Bonhomme ${ }^{2} \cdot$ J. Russell $^{3} \cdot$ E. Stillman $^{4} \cdot$ T. S. George ${ }^{3} \cdot$ L.

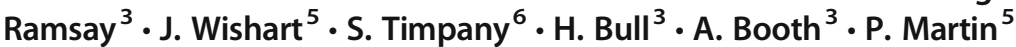

1 Department of Archaeology, University of Sheffield, Sheffield, South Yorkshire S1 3NJ, UK

2 Institut des Sciences de l'Evolution-Montpellier, Université de Montpellier, 34095 Montpellier Cedex 2, France

3 The James Hutton Institute, Dundee DD2 5DA, UK

4 School of Mathematics and Statistics, University of Sheffield, Sheffield S3 7RH, UK

5 Agronomy Institute, Orkney College, University of the Highlands and Islands, Kirkwall KW15 1LX, UK

6 Archaeology Institute, Orkney College, University of the Highlands and Islands, Kirkwall KW15 1LX, UK 